

Originally published as:

Krüger, F., Weber, M., Scherbaum, F., Schlittenhardt, J. (1993): Double beam analysis of anomalies in the core-mantle boundary region. - Geophysical Research Letters, 20, 14, 14751478. 


\title{
DOUBLE BEAM ANALYSIS OF ANOMALIES IN THE CORE-MANTLE BOUNDARY REGION
}

\author{
Frank Krüger ${ }^{1}$, Michael Weber ${ }^{1}$, Frank Scherbaum ${ }^{2}$ and Jörg Schlittenhardt ${ }^{3}$
}

\begin{abstract}
Seismic P-waves from nuclear explosions at the Kazakhstan test site in Eastern Kazakhstan (KTS) observed at the Yellowknife-array (YKA, Canada) are used to analyze the structure at the base of the mantle under Severnaya Zemlya (Arctic Sea). 18 events at the Degelen subsite and 9 events at the Shagan River subsite of KTS are studied. The simple waveforms and well controlled source parameters of nuclear explosions allow the use of the events as source arrays in addition to the usual receiver array configuration. A new method (double-beamforming) integrating both concepts is presented. This method increases the resolution considerably. For the Degelen $\Leftrightarrow$ YKA path one anomalous arrival (1.9 s before PcP, slowness between P and PcP slowness) is observed. Smaller anomalous arrivals are found $6.5 \mathrm{~s}$ (Degelen $\Leftrightarrow \mathrm{YKA}$ ) and $8.1 \mathrm{~s}$ before PcP (Shagan River $\Leftrightarrow$ YKA). These anomalous phases cannot be explained with standard Earth models. They are produced by reflections from an inhomogeneity in the lowermost mantle at $(82.3 \mathrm{~N}, 107.5 \mathrm{E})$ under the area north of Severnaya Zemlya. The strong variations between the wavefields for the two source-receiver combinations indicate a heterogeneous structure in the lower mantle. The anomaly found here is located close to an anomaly in the lowermost mantle beneath the Nansen Basin.
\end{abstract}

\section{Introduction}

The structure of the core-mantle transition zone, called $D^{\prime \prime}$, is of crucial importance for the dynamic behavior of the Earth, since this region plays a vital role for processes such as mantle convection, hot spot plume generation and core cooling. Reasons for inhomogeneties in $D^{\prime \prime}$ can be manyfold and are the topic of controversy in mineral physics, geochemistry and geodynamics (see e.g. Silver et al. [1988] and Lay [1989]).

Evidence for laterally varying $\mathbf{P}$ velocity structure in the lowermost mantle from short-period P-waves was first presented by Vinnik et al. [1972] and Wright \& Cleary [1972], for further references see Weber [1993]. Previous studies of $P$-waves from earthquakes in the Northwest Pacific recorded at the GRF-array in Germany [Weber \& Davis, 1990; Weber, 1993] show an anomalous phase (PdP), i.e. a phase that cannot be explained by standard Earth models. This phase is produced by reflections from small-scale $P$ velocity anomalies below Northern Siberia and the Nansen Basin in the Arctic Sea. The extension of the anomalies under northern Siberia towards the West was analyzed by Houard \& Nataf [1992]. Vidale \& Benz [1993] found an additional anomaly under the East Siberian Sea.

Receiver arrays are used routinely in seismology. The principle of Green's function reciprocity (concept of source arrays) provides another tool making array analysis techniques applicable for clusters of sources [Spudich \& Bost-

\footnotetext{
${ }^{1}$ SZGRF, Erlangen, FRG

${ }^{2}$ Universität München, München, FRG

${ }^{3}$ BGR, Hannover, FRG
}

Copyright 1993 by the American Geophysical Union.

Paper number 93GL01311

0094-8534/93/93GL-01311\$03.00 wick, 1987; Scherbaum et al., 1991]. Nevertheless, source arrays are rarely used, especially for teleseismic distances [Goldstein et al., 1992] due to inaccuracy of hypocenter determination and large variations in waveform between different events. In the study presented here $P$ velocity anomalies at the base of the mantle are located with a double beam technique which integrates seismic source array beamforming with receiver array beamforming. This increases the slowness resolution and enhances small phases common to the source and the receiver beams. The simple waveforms and well-controlled source parameters make nuclear tests ideal events for such an analysis. Furthermore, the use of nuclear tests (instead of earthquakes) allows us to analyze regions of the lowermost mantle previously not covered. Here we present the results for the first of several such source-receiver combinations studied.

\section{Method and Data}

The YKA-array is situated on hardrock on a major tectonic shield region in the Northwest Territories, Canada [Weichert \& Whitham, 1969]. It consists of 18 shortperiod seismometers with a maximum aperture of $25 \mathrm{~km}$ (see Figure 1). The Kazakhstan test site in Eastern Kazakhstan (KTS) is located on palaeozoic sediments on the Kazakh shield at a distance of $67.4^{\circ}$ from YKA and is divided into two major subsites, the Shagan River (SHA) and Degelen (DEG) subsite (Figure 1), each covering an area of about 15 by $20 \mathrm{~km}$. The two subsites are separated about $40 \mathrm{~km}$ perpendicular to the great circle path to YKA. While a detailed model exists for the YKA crust from refraction and reflection measurements [Weichert \& Whitham, 1969; Clee et al., 1974], information about the crustal structure at KTS comes mainly from deep seismic sounding profiles near the test site [Beliasyevsky et al., 1968], inversion of teleseismic receiver functions [Priestly et al., 1988] and modeling of regional phases [Quin \& Thurber, 1992]. These studies show that both regions have high velocities and a relatively simple crustal structure. With the source-receiver combination KTS $\Leftrightarrow$ YKA it is possible to examine the lower mantle below the region of Severnaya Zemlya in the Arctic Sea (Figure 1). The lateral resolution attainable (i.e. the Fresnel zone) for $\mathrm{P}$-waves at the base of the mantle, for the typical dominant frequency of a large nuclear explosion in hardrock (about $2 \mathrm{~Hz}$ ), is an ellipse with a size of $1.5^{\circ}$ by $3^{\circ}$ (see Figure 1 ).

18 events on the Degelen subsite and 9 events from the Shagan River subsite from 1974 to 1982 produced unclipped $\mathrm{P}$-wave recordings at YKA. For these events accurate source locations are known [Lilwall \& Farthing, 1990]. The events of each subsite were used to form source arrays. This was achieved by 1 . aligning all $\mathrm{P}$-wave onsets for the events at one station, 2. delaying them, so that the Pwave reaches the source array in reciprocal geometry with the slowness and azimuth predicted by a standard earth model (IASP91; [Kennett \& Engdahl, 1991]) and 3. delay and sum the traces, for the azimuth of the great circle path, and varying slowness.

Figure 2(a) shows source array beams (hereafter called source beams) for different slownesses for station SZYKB08 (see Figure 1) for the 18 Degelen events. Figure 2(b) shows the respective receiver array configuration: one Degelen event recorded at the $18 \mathrm{YKA}$ stations. It can be seen that the $\mathrm{P}$-wave arrives roughly with the expected $\mathrm{P}$ wave slowness of $6.4 \mathrm{~s} / \mathrm{deg}$. Due to lateral inhomogeneities 




Fig. 1. Geographical distribution of sources (KTS, with subsites Shagan River (SHA) and Degelen (DEG); stars), receivers (YKA-array; full triangle) and the area of deepest penetration of the ray paths (full circles with Fresnel zone, close to Severnaya Zemlya (SEV. ZEM.)). The open squares are the locations of the lower mantle anomalies under the Nansen Basin (N.B.), northern Siberia (N. SIB.) [Weber, 1993] and the East Siberian Sea (E.S.S.) [Vidale \& Benz, 1993]. The North Pole (N.P.) is also indicated. The projection used is azimuthal equidistant, centered on $(82.3 \mathrm{~N}, 107.5 \mathrm{E})$. Inserts show the stations of the YKAarray and the event distribution at the test sites.

beneath the YKA-array the beam amplitude maximum (open arrows) shows a deviation of $+0.4 \mathrm{~s} / \mathrm{deg}$ for the receiver array [Weichert \& Whitham, 1969]. The deviation of $+0.5 \mathrm{~s} / \mathrm{deg}$ for the source array from the predicted value (IASP91) is produced by the slightly different waveforms of the nuclear tests. The most distinct phase after $P$ is $\mathrm{PcP}$ arriving in both configurations at about the predicted slowness of $4.2 \mathrm{~s} / \mathrm{deg}$ with a (PcP-P) delay time $0.5 \mathrm{~s}$ larger than the delay time according to IASP91.

While multiples in the receiver crust tend to show up more distinct in the source beams, source crust reverberations are enhanced in the receiver beams. In Figure 2(a) (source array) these multiples (M) show up $3.7 \mathrm{~s}, 8.0 \mathrm{~s}$ and $15.0 \mathrm{~s}$ after $\mathrm{P}$ with similar slowness as $\mathrm{P}$. In Figure 2(b) (receiver array) additional onsets appear $6.0 \mathrm{~s}$ and $11.4 \mathrm{~s}$ after $P$, and can be ascribed to the thick crust beneath Degelen [Quin \& Thurber, 1992]. The fact that the multiples have a slowness close to $\mathbf{P}$ indicates that the crustal layers are not (steeply) inclined.

It is straightforward to integrate both the source and receiver configuration to construct double beams (see formulas and scheme in Figure 3 ). In a first step source beams are formed in the reciprocal geometry for a certain slowness vector $v$ for each receiver array station. These source beams are then delayed and summed in conventional geometry for the receiver array side. In general the slowness vector in reciprocal geometry $v$ is not the negative of the slowness vector $\boldsymbol{u}$ in conventional geometry. For this study it was assumed that all waves propagate on the great circle path, so that only the relative distance differences between the events to each separate receiver array station have to be taken into account.

Figure 2(c) shows the double beams for Degelen $\Leftrightarrow$ YKA. The outstanding feature is a precursor (left full triangle) 1.9 ( \pm 0.1$) \mathrm{s}$ ahead of $\mathrm{PcP}$ with a slowness slightly larger than the PcP slowness $\left(\mathrm{u}_{\text {prec }}=5.2 \pm 0.2 \mathrm{~s} / \mathrm{deg}\right)$. This precursor is less pronounced in Figures $2(a)$ and (b). About 2 $s$ after PcP a smaller phase with about the PcP slowness can be seen (right full triangle, Figure 2(c)). A third, less distinct arrival $6.5 \mathrm{~s}$ ahead of $\mathrm{PcP}$ ( $\mathrm{PdP}$, open triangle) shows a diminished slowness compared with the $\mathbf{P}$ slowness $(u=5.8 \pm 0.3 \mathrm{~s} / \mathrm{deg})$.
For the Shagan River $\Leftrightarrow$ YKA double beam combination (Figure 2(d)) only one PcP precursor (PdP, open triangle) is visible $8.1 \mathrm{~s}$ ahead of $\mathrm{PcP}$ in the double beam section with a slowness of about $5.8 \pm 0.2 \mathrm{~s} / \mathrm{deg}$. The $\mathrm{PcP} / \mathrm{P}$ amplitude ratio for the two double beam combinations is 0.09 and 0.25 , respectively. Similar variations in the amplitude ratios for events at large distances were also found for NORSAR and GRF [Schlittenhardt, 1986].

\section{Interpretation}

We interpret the anomalous arrivals in Figure 2 to be caused by an inhomogeneity in $D^{\prime \prime}$. As a first step in the interpretation synthetic seismograms were used to construct 1-D models for both paths. The best fitting 1-D model for the lower mantle between Shagan River $\Leftrightarrow$ YKA has a $1.5 \%$ velocity jump at $2711 \pm 10 \mathrm{~km}$ depth; i.e. $178 \mathrm{~km}$ above the CMB (Phase used: open triangle in Figure 2(d)). The path Degelen $\Leftrightarrow \mathrm{YKA}$ can be modelled best with a model, which has a discontinuity at $2758 \pm 10 \mathrm{~km}$ depth $(131 \mathrm{~km}$ above the CMB) with a velocity jump of $0.7 \%$ (Phase used: open triangle in Figure 2(c)).

The most distinct and unusual feature in Figure 2(c) is the occurence of two additional phases about $2 \mathrm{~s}$ before and after PcP. A 1-D model able to explain the travel time of the precursor to $\mathrm{PcP}$ (left full triangle, $1.9 \mathrm{~s}$ before $\mathrm{PcP}$ ), would have a discontinuity $40 \mathrm{~km}$ above the core-mantle boundary (CMB). Such a 1-D model cannot explain the third arrival (right full triangle, $2.0 \mathrm{~s}$ after $\mathrm{PcP}$ ) and also is not able to reproduce the correct amplitude of the $\mathrm{PcP}$ precursor (1.9 s before $\mathrm{PcP}$ ).

This fact and the lack of distinct additonal phases before and after PcP for the Shagan River $\Leftrightarrow$ YKA combination (Figure 2(d)) indicates, that a 3-D structure is responsible for the strong variations in the observed wavefields (Figure 2(c) versus Figure 2(d)). Topography on the CMB and/or lateral inhomogeneities in $D^{\prime \prime}$ are possible explanations, but the incomplete azimuthal coverage prevents a $3-D$ modeling attempt at present.

\section{Discussion and Conclusion}

Nuclear explosions used as source arrays combined with receiver arrays allow the detection of velocity anomalies in the lowermost mantle. The integration of source and receiver array beamforming (double beam concept) leads to a remarkable improvement in resolution.

The region in the lower mantle which is covered by the paths from KTS to YKA is close to an area, where a Pwave velocity anomaly was detected previously (Nansen Basin (N.B.) in Figure 1). In that study earthquakes from the Aleutians recorded at the GRF-array in Germany were used. The anomaly under the Nansen Basin has a reflector depth of $2612 \pm 20 \mathrm{~km}$ and a velocity contrast of about $3 \pm 1.5 \%$, [Weber, 1993]. For the anomaly under the Nansen Basin deviations from the great circle path are observed for $P d P$, indicating $3-D$ effects. The lowermost mantle under the Severnaya Zemlya region has a strongly varying structure, which finds its expression in the different wavefields for the two double beams in Figure 2. The weaker PdP onsets observed $6.5 \mathrm{~s}$ ahead of PcP for Degelen $\Leftrightarrow$ YKA and 8.1 s ahead of PcP for Shagan River $\Leftrightarrow \mathrm{YKA}$, if modelled with $1-\mathrm{D}$ models, indicate a reflector more than $100 \mathrm{~km}$ deeper than in the Nansen Basir region with a velocity contrast at the discontinuities two to three times smaller than in PNAN. The fact that the two models under Severnaya Zemlya are remarkably different. even as Fresnel zones of the $\mathrm{P}$-waves almost completely overlap, indicates that the velocity structure at the base of the mantle is strongly inhomogeneous on a scale lengtl of a few tens to hundreds of kilometers. 
Krüger et al.: Double Beam Analysis of $D^{\prime \prime}$
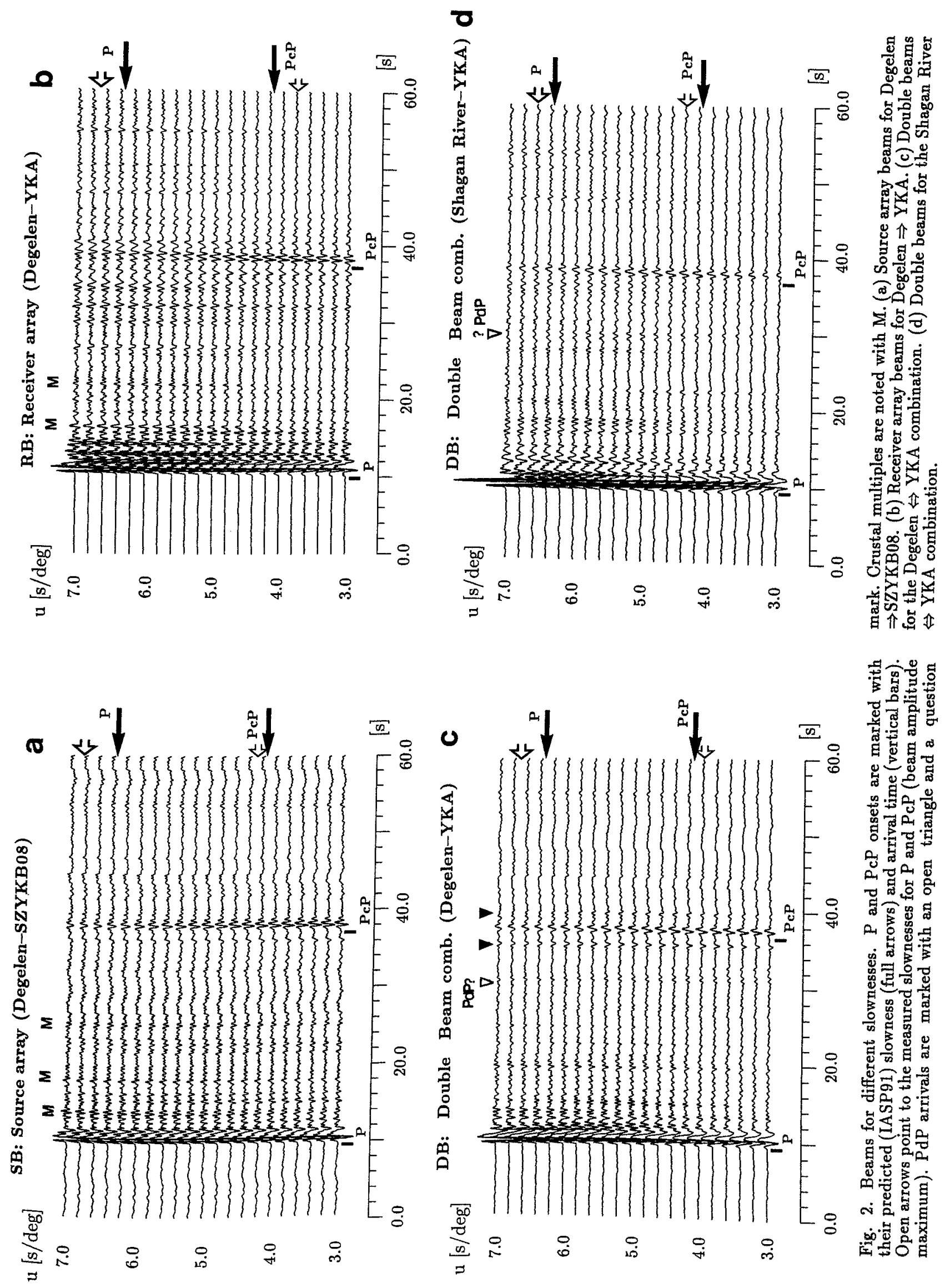


$$
\begin{gathered}
\text { Source Beamforming } \\
S B_{l i}\left(v_{l}, t\right)=\frac{1}{K} \sum_{k=1}^{K} a(k) x_{i k}\left(t-\kappa_{k l}\right)
\end{gathered}
$$

$v_{l}=$ slowness vector in reciprocal geometry

(negative slowness vector under which the source signals leave the source array assuming identical origin times)

$l=1, L$ (number of source beams)

$\kappa_{k l}=\left(s_{k}-s_{0}\right) v_{l}=$ time delay in reciprocal

geometry at $s_{0}$ with respect to $s_{k}$

$\boldsymbol{s}_{k}=$ source coordinate vector

$s_{0}=$ coordinate vector of reference source

$a(k)=$ source amplitude equalisation factor
Receiver Beamforming

$$
R B_{j k}\left(u_{j}, t\right)=\frac{1}{I} \sum_{i=1}^{I} x_{i k}\left(t-\tau_{i j}\right)
$$

$u_{j}=$ slowness vector in conventional geometry

$j=1, J$ (number of receiver beams)

$\tau_{i j}=\left(r_{i}-r_{0}\right) u_{j}{ }^{\prime}=$ time delay in conventional geometry at $r_{0}$ with respect to $r_{i}$

$r_{0}=$ coordinate vector of reference station

$r_{i}=$ station coordinate vector

$$
\begin{aligned}
& k=1, K \text { (number of sources) } \\
& i=1, I \text { (number of stations) } \\
& x_{i k}(t)=\text { seismogram of source } s_{k} \text { at station } r_{i}
\end{aligned}
$$

Special case: $\boldsymbol{v}_{\boldsymbol{l}}=\boldsymbol{u}_{j}$

$$
D B_{j l}\left(\boldsymbol{u}_{j}, \boldsymbol{v}_{l}, t\right)=\sum_{i=1}^{I} S B_{l i}\left(\boldsymbol{v}_{l}, t-\tau_{i j}\right)
$$

Fig. 3. Schematic representation of the analysis method. Upper left: Source array beamforming. Upper right: Receiver array beamforming. Bottom: Double beamforming by integrating source and receiver array beamforming.

Acknowledgements. We thank W. Hanka and the Geological Survey of Canada for supplying us with the data and K. Stammler for programs to process and analyze the data. We also wish to thank Th. Lay, A. Rietbrock and an anonymous referee for comments to this paper and the Deutsche Forschungsgemeinschaft for financing this research.

\section{References}

Beliasyersky, N.A., A.A. Borisov, I.S. Volvosky, \& Y.K. Schukin, Transcontinental crustal sections of the USSR and adjacent areas, Can. J. Earth Sci., 5, 1067-1087, 1968.

Clee, T.E., K.G. Barr \& M.J. Berry, Fine structure of the crust near Yellowknife, Can. J. Earth Sci., 11, 1534$1549,1974$.

Goldstein, P., W.R. Walter, \& G. Zandt, Upper mantle structure beneath central Eurasia using a source array of nuclear explosions and waveforms at regional distances, J. Geophys. Res., 97, 14097-14115, 1992.

Houard, S., \& H.-C. Nataf, Further evidence for the 'Lay discontinuity' beneath northern Siberia and the North Atlantic from short-period $\mathrm{P}$-waves recorded in France, Phys. Earth Planet. Int., 72, 264-275, 1992.

Kennett, B.L.N., \& E.R. Engdahl, Traveltimes for global earthquake location and phase identification, J. Geophys., 105, 429-465, 1991.

Lay, T., Structure of the core-mantle transition zone: a chemical and thermal boundary layer, Eos, 70 , No. 4, Jan. 24., 49, 1989.

Lilwall, R.C., \& J. Farthing, Joint epicentre determination of Soviet underground nuclear explosions 1973-89 at the Semipalatinsk testsite, AWE Report No. O 12/90, HMSO, London, 1990.

Priestly, K.F., G. Zandt, \& G.E. Randall, Crustal structure in Eastern Kazakh, U.S.S.R. from teleseismic receiver functions, Geophys. Res. Lett., 15, 613-616, 1988.

Quin, R.H., \& C.H. Thurber, Seismic velocity structure and event relocation in Kazakhstan from secondary $P$ phases, Bull. Seism. Soc. Amer., 82, 2494-2510, 1992.
Scherbaum, F., D. Gillard, \& N. Deichmann, Slowness power spectrum analysis of the coda composition of two microearthquake clusters in northern Switzerland, Phys. Earth and Plan. Int., 67, 137-161, 1991.

Schlittenhardt, J., Investigation of the velocity- and $Q$ structure of the lowermost mantle using $P c P / P$ amplitude ratios from arrays at distances of $70^{\circ}-84^{\circ}, J$. Geophys., 60, 1-18, 1986.

Silver, P.G., R. Carlson, \& P. Olson, Deep slabs, geochemical heterogeneity and the large-scale structure of mantle convection: Investigation of an enduring paradox, Ann. Rev. Earth planet. Sci., 16, 477-541, 1988.

Spudich, P., \& T. Bostwick, Studies of the seismic coda using an earthquake cluster as a deeply buried seismograph array, J. Geophys. Res., 92, 10526-10546, 1987.

Vidale, J.E., \& H. Benz, Mapping fine structure near the base of the mantle, Nature, 361, 529-532, 1993.

Vinnik L.P., A.A. Lukk, \& A.V. Nikolaev, Inhomogeneities in the lower mantle, Phys. Earth Planet. Int., 5, 328331, 1972.

Weber, M., $P$ and $S$ wave reflections from anomalies in the lowermost mantle, Geophys. J. Int., in press, 1993.

Weber, M., \& J.P. Davis, Evidence of a laterally variable lower mantle structure from $\mathrm{P}$ - and S-waves, Geophys. $J$. Int., 102, 231-255, 1990.

Weichert, D.H., \& K. Whitharn, Calibration of the Yellowknife seismic array with first zone explosions, Geophys. J. R. astr. Soc., 18, 461-476, 1969.

Wright, C., \& J.R. Cleary, $P$ wave travel-time gradient. measurements for the Warramunga seismic array and lower mantle structure, Phys. Earth Planet. Int., 5 213-230, 1972.

F. Krüger and M. Weber, Seismol. Zentralobs. GRF Krankenhausstr. 1-3, D-8520 Erlangen, FRG.

F. Scherbaum, Institut für Allgemeine und Angewandte Geophysik, Theresienstr. 41, D-8000 München 2, FRG.

J. Schlittenhardt, Bundesanstalt für Geowissenschafter und Rohstoffe, Stilleweg 2, D-3000 Hannover 51, FRG.

(Received April 20, 1993; accepted May 17, 1993.) 